\title{
TIPOLOGI BANGUNAN DI PERMUKIMAN BANTARAN SUNGAI BERDASARKAN LOKASI DAN JENIS KONSTRUKSI (STUDI KASUS: PERMUKIMAN BANTARAN SUNGAI KAHAYAN, PALANGKARAYA)
}

\author{
Nindita Kresna Murti \\ Magister Teknik Arsitektur, Universitas Diponegoro, Semarang \\ ninditakresnamurti@gmail.com
}

\section{Atiek Suprapti}

Magister Teknik Arsitektur, Universitas Diponegoro, Semarang atiekbudiarto@gmail.com

\section{Agung Budi Sardjono}

Magister Teknik Arsitektur, Universitas Diponegoro, Semarang agungbsardjono@gmail.com

Abstrak

Rumah yang berada di permukiman bantaran Sungai memiliki keunikan dan karakter tersendiri, hal ini dikarenakan fisik bangunan rumah menyesuaikan dengan kondisi dan lingkungan di daerah bantaran sungai. Pulau Kalimantan dibelah oleh sungai - sungai besar yang memiliki keunikan dan kondisi lingkungan yang berbeda satu dan yang lain, misalnya Sungai Kahayan yang membelah kota Palangkaraya memiliki kondisi dimana ketinggian pasang surut air sungai yang sangat tinggi dan terdapat permukiman awal terbentuknya Kota Palangkaraya. Bangunan rumah di permukiman yang berada di bantara Sungai Kahayan memiliki 3 segmen, yaitu 1) bangunan rumah yang bearda di atas air (apung/lanting), 2) bangunan rumah yang berada di bantaran/transisi antara air dan daratan (panggung), 3) bangunan rumah yang berada di darat. Metode yang di gunakan adalah metode kualitatif deskriptif, metode ini bertujuan untuk mengambarkan dan mendeskripsikan tipologi berdasarkan jenis struktur dan ruang pada bangunan di permukiman ini. Tujuan Penulisan artikel ini untuk mengetahui tipologi bangunan rumah di bantaran Sungai Kahayan yang terdiri dari segmen bangunan di atas air, panggung, dan bangunan yang di darat, berdasarkan konfigurasi bentuk dan ruang (spatial structure). Hasil dari penulisan paper ini adalah lokasi rumah dan perkembangan permukiman ini mempengaruhi tipologi yang terbentuk.

Kata-kata Kunci: Permukiman Tepi Air, Sungai Kahayan, Tipologi

\section{BUILDINGS TYPOLOGY IN RIVERFRONT SETTLEMENTS BASED ON LOCATION AND TYPE OF CONSTRUCTION (CASE STUDY: KAHAYAN RIVER SIDE SETTLEMENTS, PALANGKARAYA)}




\begin{abstract}
Houses in riverbank settlements have their uniqueness and character, and this is because the physical building of the house adapts to the conditions and environment in the riverbanks. Borneo is divided by large rivers that have unique and different environmental conditions; for example, the Kahayan River, which divides the city of Palangkaraya has a condition where the tidal height of the river is very high, and early settlements forming the City of Palangkaraya. Houses in settlements located on the riverbanks of the Kahayan have 3 segments, 1) Houses that are built on water (floating/lanting), 2) Houses that are located on the banks/transitions between water and land (stage), 3) house building in the land. The method used is a descriptive qualitative method; this method aims to describe and describe typologies based on the type of structure and space in buildings in this settlement. Purpose The writing of this paper seeks to find out the typology of house buildings on the banks of the Kahayan river, which consists of building segments on water, stage buildings, and buildings on the land, based on their spatial structure configurations. The results of this paper are the location of the house and the development of this settlement affect the typology that is formed.
\end{abstract}

Keywords: Waterfront settlement, Kahayan River, Typology

\title{
1. Pendahuluan
}

Permukiman dan kota di Kalimantan memiliki kondisi geografis yang spesifik dan unik, yaitu lokasi permukiman terkonsentrasi di bantaran sungai, daerah rawa, dan hutan belantara. Sungai dan Pulau Kalimantan tidak dapat dipisahkan (Sunarningsih, 2011) Kalimantan terbelah oleh sungai sungai besar, yaitu Sungai Barito, Sungai Mahakam, dan Sungai Kahayan dan lokasi awal mula munculnya permukiman di Kalimantan(Hadinata \& Mentayani, 2018). Arsitektur permukiman merupakan hasil dari adaptasi manusia terhadap lingkungan (Sari, 2014), kegiatan masyarakat yang dilakukan di sungai ini secara terus menerus menghasilkan budaya kehidupan di sungai, kebudayan sungai adalah sebagai bagian dari cara hidup (Kusnoto \& Purmintasari, 2018) yang sudah dilakukan secara turun temurun sejak dahulu (Dahliani \& Soemarno, 2016). Hasil dari perilaku dan kegiatan masyarakat inilah yang menghasilkan pola - pola permukiman dengan berbagai komponen dan fasilitas penunjangnya (Afdholy, Wulandari, \& Utami, 2019) namun juga tak lepas terbentuknya pola pemukiman terkait dengan perubahan keadaan sungai dan iklim (Balbo, Persson, \& Roberts, 2010). Permukiman bantaran sungai dan budaya sungai menjadi ciri khas khusus pada permukiman bantaran sungai kahayan, hal ini menjadikan daya tarik tersendiri dengan unsur kelokalannya. Budaya pada permukiman ini bervariasi, karena masyarakat yang menempati tidak hanya warga asli Kota Palangkaraya, namun warga luar yang ber-urbanisasi karena ingin mencari kehidupan yang lebih baik (Collinson, Tollman, \& Kahn, 2007). Karakteristik umum banguan dan permukiman di tepi sungai, meliputi (1) sejarah perkembangan permukiman, (2) antar bangunan yang cenderung rapat (kepadatan tinggi) kumuh, (3) pola yang mengikuti kontur, (4) orientasi bangunan yang menghadap ke air/Sungai (Suprijanto, 2001).

Tipologi terbagi atas kata 'type' bahasa yunani (typos) dan 'Logy'. 'Typos' yang memiliki pengertian gambaran, jenis, dan bentuk maupun karakteristik pada obyek, sedangkan 'Logy' adalah ilmu, sehingga kata Tipologi di artikan sebagai ilmu yang mempelajari gambaran, jenis, dan bentuk atau karakteristik dari objek (Suharjanto, 2013). Tipologi diartikan sebagai cara untuk memilah dan mengelompokan suatu objek atau jenis (Rengkung, Antariksa, Suryono, Nugroho, \& Kindangen, 2018) yang didasarkan oleh kesamaan sifat-sifat dasar, kecenderungan untuk mengelompokan dan 
nengklasifikasikan unsur-unsur dan faktor - faktor dalam yang random/ acak, baik berdasarkan pada posisi perletakkan (lokasi), maupun karakteristik visual /fasad (Ching, 1979).

Banyak studi yang telah membahas tentans tipologi pada sebuah permukiman di Indonesia maupun di luar negeri, namun masih belum banyak yang membahas sisi tipologi dari segmen bangunan/konstruksi bangunan. Berdasarkan studi (Afdholy, 2019) yang membahas Tipologi dari sisi fungsi bangunan/rumah, studi (Setiadi, 2014) membahas tipologi permukiman yang di lihat dari sisi kualitas hidup dari aspek fisik, sosial, budaya dan ekonomi. Selanjutnya berdasarkan studi (Hamidah, Rijanta, Setiawan, \& Marfai, 2014) yang memiliki obyek penelitian yang sama, membahas pola permukiman yang di identifikasi dari model permukiman dari aspek fisik dan nonfisik. Pada lokasi penelitian belum ada yang membahas tentang tipologi yang di lihat dari sisi kontruksi bangunan, yang di dasari dari lokasi bangunan itu berdiri.

Dengan melihat gap tersebut, maka paper ini bertujuan mendeskripsikan tipologi bangunan rumah tinggal yang ada pada permukiman tepi sungai Kahayan di lihat dari sisi jenis kontruksi bangunan. Permukiman ini memiliki keunikan yaitu, terletak pada jenis bangunannya, yang tidak semua pemukiman tepi air yang ada di Kalimantan memilikinya. Pada Permukiman ini karakteristik model permukiman tepian Sungai Kahayan memiliki tiga tipe, yaitu: (1) rumah rakit (raft houses), dan (2) rumah tiang (pillar houses), dan (3) rumah darat (land houses). Munculnya jenis - jenis bangunan, di karenakan penempatan lokasi bangunan yang berbeda, bangunan dengan konstruksi lanting / apung berada di atas air, bangunan dengan konstruksi panggung terletak di area transisi antara air dan daratan, bangunan dengan konstruksi beton berada di daratan. Permukiman bantaran Sungai Kahayan di Kota Palangkaraya merupakan permukiman awal yang memiliki keunikan yaitu pola permukiman memanjang dan mengikuti bentuk aliran sungai (Hamidah, Rijanta, Setiawan, \& Marfai, 2014).

\section{Metode}

Metode penelitian yang di gunakan adalah metode penelitian kualitatif deskriptif. Di mana penelitian deskriptif kualitatif ini ditujukan untuk mendeskripsikan/ menjelaskan maupun menggambarkan fenomena-fenomena yang terjadi, baik yang fenomena yang bersifat alamiah maupun fenomena yang bersifat nonilmiah/ hasil rekayasa manusia, metode penelitian kualitatif deskriptif ini lebih memperhatikan pada aspek - aspek dan faktor pembentuk karakteristik, kualitas, dan keterkaitan antar kegiatan yang ada .

Selain itu, Penelitian kualitatif deskriptif tidak memberikan perlakuan khusus, maupun berupaya memanipulasi atau melakukan pengubahan pada variabel- variabel yang akan diteliti, metode kualitatif deskriptif bertujuan untuk menggambarkan dan menjabarkan suatu kondisi yang apa adanya/real di suatu lokasi amatan. Pengolahan data di peroleh dari literatur, penelitian dan teori - teori yang sudah ada /terdahulu, dan data diperoleh dan di analisa denagan dilakukan melalui proses observasi di lapangan, wawancara warga, dan dokumentasi pada bangunan permukiman tepi air.

\section{Tahapan Pengolahan Data dan Analisa}

1. Wawancara yang dilakukan pada narasumber yaitu warga permukiman tepi sungai Kahayan dan petugas kelurahan untuk mengetahui perkembangan permukiman

2. Data yang di peroleh dikelompokan sesuai dengan kategori informasinya. kemudian data- data tersebut di reduksi/ seleksi data sesuai tujuan penelitian.

3. Membuat peta lokasi penelitian untuk dapat melihat tipologi ruang yang terbentuk.

4. Menganalisa jenis konstruksi dan mengelompokkan jenis konstruksi yang di gunakan pada rumah di permukiman tersebut, yaitu: Apung, panggung, dan darat. 
5. Hasil analisa dibuat kesimpulan.

\section{Hasil dan Pembahasan Lokasi Penelitian}



Gambar 1.Peta Lokasi Penelitian Sumber: Data Penulis, 2019

Penelitian ini dilakukan di permukiman bantaran Sungai Kahayan, Kota Palangkaraya, Kalimantan Tengah, Indonesia dengan koordinat $2^{\circ} 12^{\prime} 21.9^{\prime \prime} \mathrm{S} 113^{\circ} 55^{\prime} 39.5^{\prime \prime E}$ yang secara geografis/ letaknya, kawasan permukiman ini berada di tikungan sungai dan bantaran Sungai Kahayan yang tidak terlalu jauh dengan pusat Kota Palangkaraya $\pm 2 \mathrm{~km}$. Pemilihan lokasi studi ini dikarenakan merupakan permukiman awal terbentuknya Kota Palangkaraya yang terletak di bantaran Sungai Kahayan (lihat Gambar 1) dan memiliki 3 segmen bangunan, yaitu Segmen darat, Segmen Panggung, dan Segmen Apung (Lanting) (lihat Gambar 2). Tipologi akan mengklasifikasikan, mengkelompokkan,dan mengkelaskan berdasarkan aspek - aspek, antara lain: (1) fungsi, yang meliputi jenis struktural, fungsi ruang, dan lain - lain, (2) aspek geometrik yang meliputi layout/tatanan, bentuk, prinsip, dan lain - lain, (3) aspek langgam, yang meliputi lokasi /letak geografis, periode bangunan/ jaman, kondisi politik, culture dan budaya, dan lain - lain (Sulistijowati, 1991). 


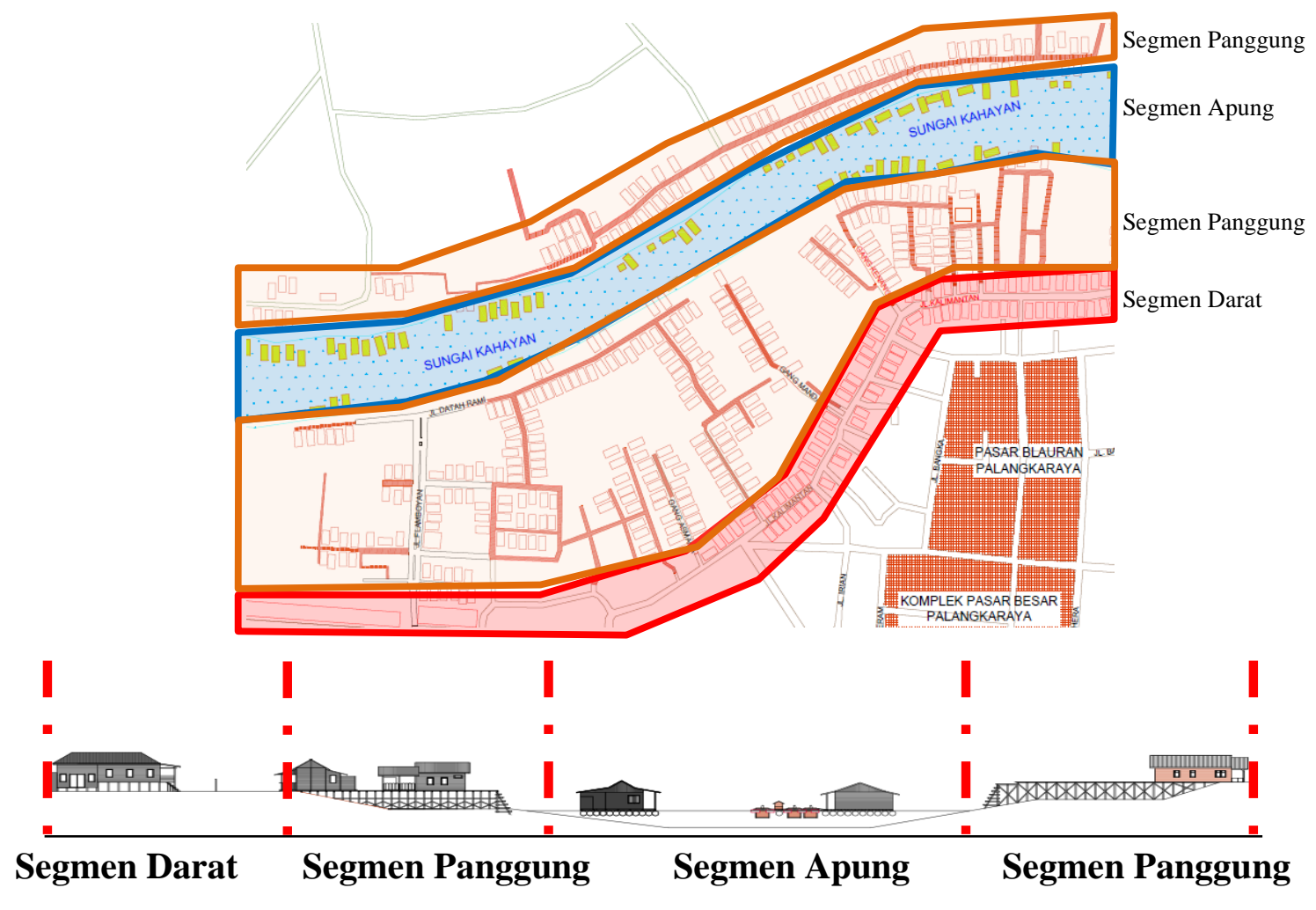

Gambar 2. Segmen Bangunan

Sumber: Data Penulis, 2019

Tabel 1. Gambar Segmen Bangunan Si Permukiman Tepi Sungai Kahayan

\begin{tabular}{lll}
\hline Segmen & Gambar \\
\hline Apung &
\end{tabular}
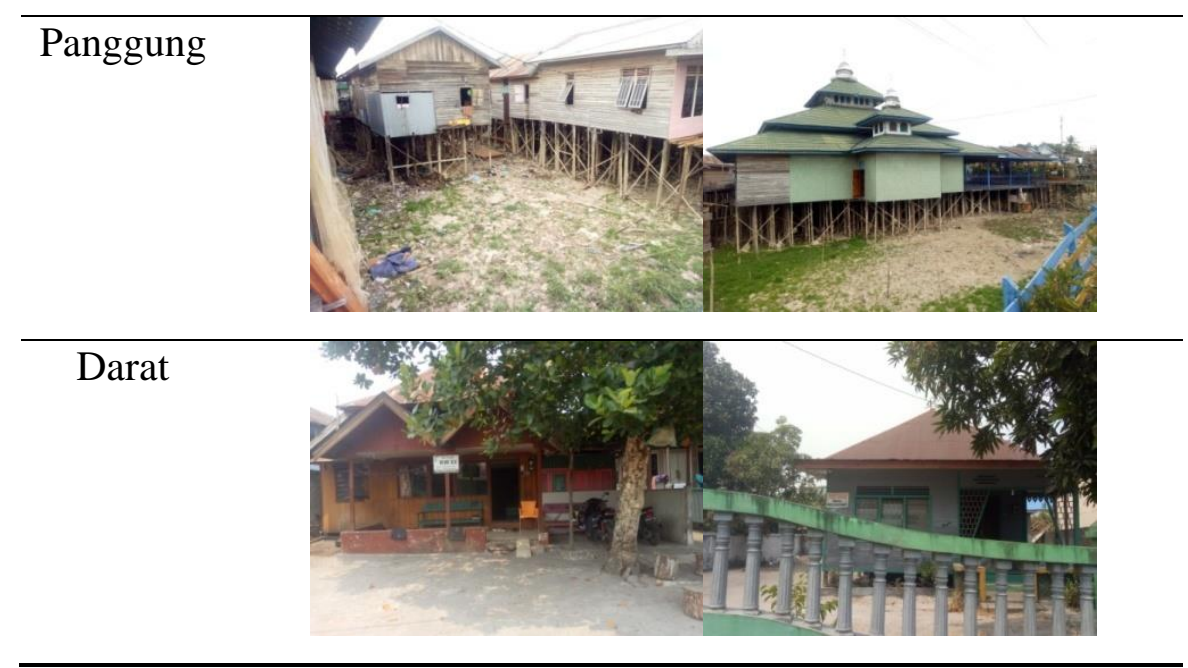

Sumber: Dokumentasi Penulis, 2019 
Awal permukiman ini di huni oleh masyarakat etnis dayak, namun saat ini etnis Banjar menjad etnis mayoritas yang mendiami permukiman ini. Hal ini dikarenakan terjadinya urbanisasi dari Kalimantan Selatan ke Kalimantan Tengah. Mayoritas kegiatan dan mata pencaharian warga serta keseharian penduduknya didominasi oleh nelayan ikan, pedagang, dan peternak ikan (keramba). Namun banyak warga juga yang memiliki usaha sampingan sendiri seperti membuka warung snak dan lauk pauk yang di dirikan di teras, yang berada depan rumah dan warga juga membuka usaha persewaan klotok untuk kegiatan pariwisata karena di sungai kahayan juga merupakan tujuan utama wisata kota.

Pola permukiman pada suatu kawasan tidak terbentuk dengan sedirinya (Abdullah, 2000) aspek ini dapat di lihat dari lokasi, langgam, fungsi, skala, geometrik, warna, bentuk, garis, kebudayaan, sosial-politik, tekstur, dan lain -lain. Pola di permukiman ini terbentuk dari aspek lokasi, dan konstruksi bangunan, bangunan rumah dengan konstruksi panggung yaitu bangunan rumah yang terletak/ berada di bantaran/area transisi antara daratan dan sungai, dimana bangunan rumah ini merupakan massa bangunan rumah semi permanen. Sedangkan bangunan rumah dengan mengunakan struktur konstruksi apung adalah rumah yang terletak di atas permukaan air sungai. Rumah apung ini dapat berpindah tempat dan mengikuti arus air sungai, supaya banguan rumah apung tidak berpindah tempat/hanyut ke tempat yang tidak di inginkan, maka rumah apung ini menambatkan tali pada rumah panggung atau titian jalan di sekitarnya.

\section{Perkembangan Permukiman}

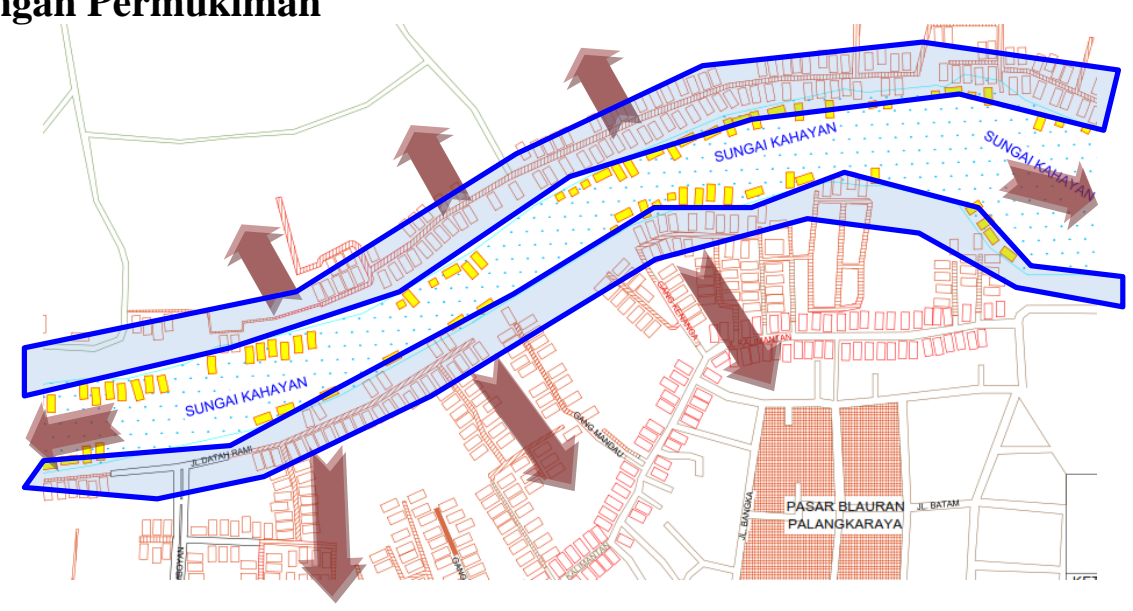

Keterangan :

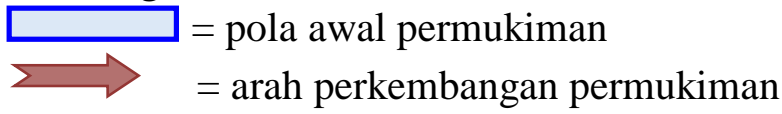

Gambar 3. Perkembangan Permukiman Tepi Sungai Kahayan

Sumber: Analisa Penulis, 2019

Perkembangan bangunan rumah pada permukiman di bantaran Sungai Kahayan pada awalnya mengikuti aliran arus Sungai Kahayan, namun dengan perkembangan saat ini, permukiman mulai tumbuh ke arah daratan (lihat gambar 3). Sungai pada masanya sebagai akses utama transportasi, ssialisasi dan juga menjadi sumber air untuk keperluan hidup (Putro \& Nurhamsyah, 2006) sehingga permukiman ini awalnya berada di bantara sungai dimana semua keperluan terpenuhi. Perkembangan permukiman ini yang menuju kedaratan mempengaruhi tipologi ruang, yakni dimana adanya perubahan tipologi ruang dari yang hanya awalnya hanya linier, karena mengikuti aliran air sungai, namun berkembang dengan adanya invansi/perkembangan permukiman ini yang menuju kedaratan. 
Pembangunan rumah sudah mulai menuju ke daratan, ini dikarenakan sungai yang sudah tidak lagi penjadi pusat/sumber kehidupan utama masyarakat. Kemudahan akses transportasi menuju fasilitas umum seperti rumah sakit, pasar, fasilitas pendidikan, dll yang berada di pusat kota Palangkaraya menjadi alasan perkembangn bangunan rumah menuju kedaratan.

\section{Tipologi ruang pada permukiman bantaran Sungai Kahayan}

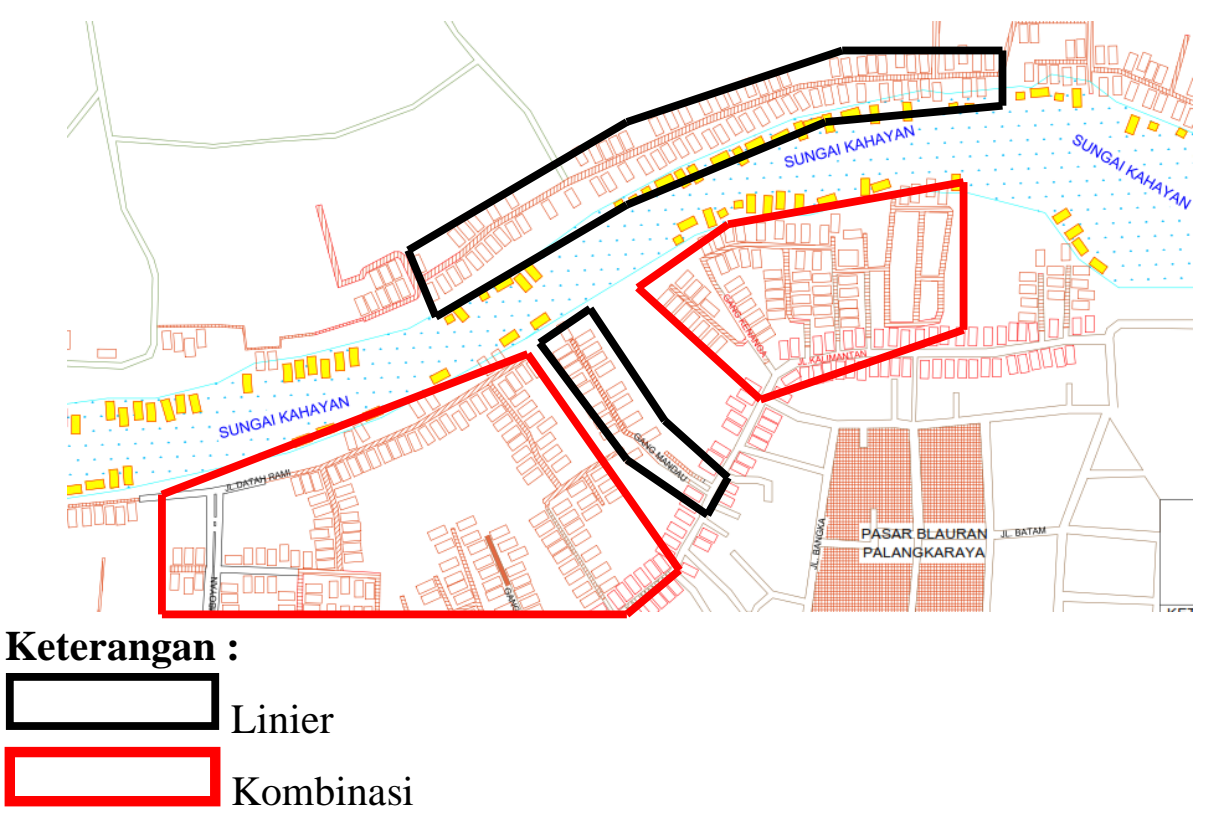

Gambar 4. Struktur Ruang Pada Permukiman Tepi Sungai Kahayan

Sumber: Analisa Penulis, 2019

Berdasarkan teori Taylor L (1980) membagi struktur ruang pada suatu permukiman menjadi 3, yaitu: (1) linier, (2) cluster, (3) kombinasi. Struktur ruang yang terbentuk pada permukiman informal ini ada 2 dari 3 struktur ruang, yaitu linier dan kombinasi (lihat Gambar 4).

1. Linier

Pola Linier pada permukiman ini terdapat pada kawasan Pahandut, dan pahandut Sebrang. Pada Pahandut Sebrang hal ini di karenakan pada permukiman tersebut masih mengikuti arah aliran sungai Kahayan dan belum berkembang ke daratan. Pola ini terbentuk karena sungai ini menjadi sumber kehidupan utama yang melimpah dan sangat dibutuhkan untuk berbagai keperluan. Sehingga terbentuk pola permukiman yang mengikuti arus sungai. Permukiman penduduk di Sungai Kahayan terbentuk di sisi kanan dan kiri sungai dan memanjang dari hulu hingga ke hilir.

2. Kombinasi

Pola Kombinasi pada permukiman ini terdapat pada kelurahan Pahandut. Pola Kombinasi terbentuk karena adanya invasi bangunan ke arah daratan, sehingga adanya pertumbuhan dan perkembangan pembangunan bangunan - bangunan rumah mengarah ke daratan.

\section{Struktur Konstruksi Bangunan Permukiman}

Keunikan bangunan pada permukiman bantaran Sungai Kahayan, adalah terdapat 2 jenis struktur bangunan yang khas bangunan bantaran sungai, yaitu struktur apung dan struktur panggung. Namun dengan berkembangnya permukiman dengan pesat, pembangunan bangunan mulai menuju ke daratan. Sehingga terdapat 3 jenis struktur bangunan pada permukiman tepi sungai kahayan tersebut (lihat Gambar 2), yakni: 
1) Struktur Apung/ lanting, bangunan rumah yang berada di atas air. Struktur konstruksi pondasi pada rumah apung/ lanting, menggunakan kayu yang di susun, kayu log/bulat dengan jenis kayu meranti berdiameter 80 - $100 \mathrm{~cm}$ namun karena semakin susah dalam mendapatkan log kayu dan mahal, maka ada bangunan rumah yang mengganti log kayu dengan tong - tong besi (lihat Tabel 1). Log kayu maupun tong besi kosong disusun sejajar mengikuti arah aliran arus sungai. Pemilihan kayu meranti, karena kayu jenis ini ringan dan dapat mengambang serta tahan lama, cocok difungsikan untuk kontruksi rumah lanting/ apung .

2) Struktur Panggung, di gunakan pada bangunan yang berada di area transisi antara darat dan air. Struktur konstruksi pondasi rumah panggung/tiang menggunakan material kayu, jenis kayu yang digunakan yakni menggunakan kayu dengan jenis ulin/ kayu besi dan sering juga menggunakan kayu dengan jenis rangas. Untuk memperkuat pondasi agar tidak geser digunakan suai/pengikat dari kayu untuk membantu menyangga dan mempertahankan pondasi (lihat Tabel 1) .

3) Struktur beton, di gunakan pada mangunan moderen yang berada di darat. Materi bahan bangunan yang di gunakan untuk rumah darat sudah tidak hanya menggunakan materi kayu, namun materi bangunan sudah banyak yang menggunakan beton (lihat Tabel 1).

Tabel 2. Orientasi Bangunan

\section{Peta Lokasi}






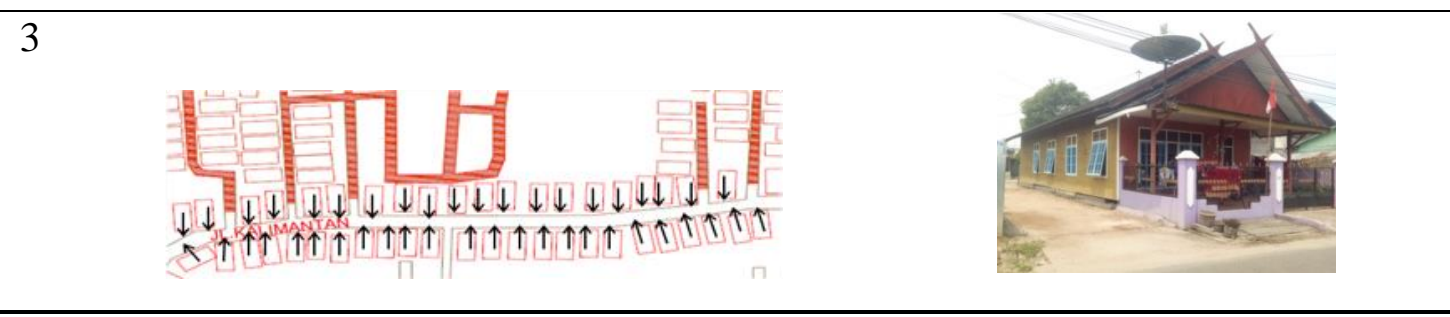

Sumber: Analisa Penulis,2019

Bangunan rumah di permukiman bantaran Sungai Kahayan ini dibagi atas 3 (tiga) segmen/ lokasi yaitu: (1) bangunan rumah apung/ lanting, (2) bangunan rumah panggung, dan (3) bangunan rumah darat (modern) (lihat gambar 2).

1. Pada bangunan rumah apung/ lanting, arah fasade/ muka bangunan menghadap ke arah tengah sungai Kahayan, hal ini dikarenakan sarana utama transportasi pada awalnya untuk rumah apung menggunakan klotok/ kapal kecil. Struktur konstruksi pondasi pada rumah apung/ lanting, menggunakan kayu yang di susun, kayu log/ bulat dengan jenis kayu meranti berdiameter $80-100 \mathrm{~cm}$ namun karena semkin susah dalam mendapatkan log kayu dan mahal, maka ada bangunan rumah yang mengganti log kayu dengan tong - tong besi. Materi pondasi disusun secara sejajar dengan arah aliran arus sungai. Jenis Kayu meranti dipilih karena kayu jenis ini ringan, tahan lama dan cocok untuk kontruksi rumah lanting (lihat Tabel 2). Ruang pada rumah segmen apung mengalami perubahan dimana hirarki akses utama masuk kedalam rumah menggunakan pintu belakang, dan tidak menggunakan pintu depan yang menghadap sungai, hal ini dikarenakan sungai yang sudah tidak menjadi akses transportasi utama. Sehingga depan rumah sudah berubah menjadi belakang rumah, dan merubah fungsi teras menjadi ruang penyimpanan barang.

2. Rumah Panggung, berbeda dengan arah fasade rumah apung, rumah panggung arah fasade menghadap akses/ jalan, yang terbuat dari papan (jembatan/titian). Struktur konstruksi pondasi rumah panggung/tiang menggunakan bahan kayu, yakni menggunakan kayu dengan jenis tabalien (ulin)/ kayu besi dan sering juga menggunakan kayu dengan jenis rangas. Pada pondasi terlihat juga menggunakan suai/pengikat untuk membantu menyangga dan mempertahankan tiang-tiang pondasi agar pondasi lebih kuat dan tidak bergeser lanting (lihat Tabel 2).

3. Rumah Darat, arah fasade menghadap ke akses utama ke perkampungan ini yaitu, jalan Kalimantan. Materi bahan bangunan yang di gunakan untuk rumah darat sudah tidak hanya menggunakan materi kayu, namun materi bangunan sudah banyak yang menggunakan beton lanting (lihat Tabel 2).

\section{Kesimpulan}

Tipologi pada permukiman ini terbentuk karena adanya perbedaan lokasi berdirinya bangunan dan jenis konstruksi yng dibedakan menjadi 3, yaitu :

1. Bangunan yang berada diatas air sungai akan menggunakan struktur apung yang menggunakan material log kayu dan tong besi, dan fasad bangunan mengarah ke sungai, akses utama ke dalam bangunan sudah tidak lagi menggunakan jukung/ klotok (perahu kecil) namun sudah menggunakan jalan darat, sehingga terjadi perubahan hirarki ruang belakang bangunan menjadi akses jalan masuk utama dan fungsi teras bangunan menjadi tempat penyimpanan barang .

2. Bangunan yang berada di area transisi (bantaran sungai) manggunakan struktur panggung dikarenakan menjawab ketinggian air sungai sesuai keadaan pasang surut air sungai, dan arah 
fasad bangunan ke akses titian. Titian ini terbuat dari material kayu, namun terjadi perubahan material menjadi beton, dikarenakan harga kayu yang semakin mahal.

3. Bangunan yang berada di darat sudah menggunakan struktur beton, namun masih ada yang menggunakan struktur kayu dan berpondasi panggung, arah fasad bangunan rumah menghadap ke arah jalan raya.

a. Tipologi ruang yang terbentuk tepengaruh pada perkembangan di permukiman ini, pada awalnya bangunan rumah mengikuti arah arus sungai Kahayan, sehingga hanya membentuk pola linier, namun sekarang dengan adanya perkembangan menuju ke daratan maka terbentuk pola baru yaitu pola ruang kombinasi. Perkembangan permukiman menuju kedaratan dikarenakan kemudahan aksisbilitas dan lebih dekat fasilitas umum dipusat Kota Palangkaraya.

\section{Ucapan Terima Kasih}

Penulis mengucapkan terimakasih kepada kelurahan Pahandut, Kota Palangkaraya atas informasi dan data, serta warga masyarakat permukiman tepi sungai Kahayan.

\section{Daftar Pustaka}

Abdullah. (2000). Upaya Meningkatkan Income Penduduk Kawasan Penyangga Kota Melalui Penataan Prasarana Permukiman. Palu: Lemit Universitas Tadulako.

Afdholy, A. R., Wulandari, L. D., \& Utami, S. (2019). Tipologi Fungsi Rumah Tepian Sungai Di Pinggiran Kota Banjarmasin (Typology of Riverside House Function in Banjarmasin Periphery). JAMAG , Vol. 1(1):616.https://www.researchgate.net/publication/331 830330_TIPOLOGI_FUNGSI_RUMAH_TEPI AN_SUNGAI_DI_PINGGIRAN_KOTA_BANJ ARMASIN_Typology_of_Riverside_House_Fu nction_in_Banjarmasin_Periphery.

Balbo, A. L., Persson, P., \& Roberts, S. J. (2010). Changes in settlement patterns on the River Rena, southeast Norway: A response to Holocene climate change? The Holocene, Vol.20(6) : 917-929. DOI: 10.1177/0959683610365939.

Ching, F. (1979). Architecture Form, Space and Order. New York: Van Nostrand Reinhold.

Collinson, M. A., Tollman, S. M., \& Kahn, K. (2007). Migration, settlement change and health in postapartheid SouthAfrica: Triangulating health and demographic surveillance withnational census data. Scandinavian Journal of Public Health, Vol.35(Suppl 69): 77-84DOI: 10.1080/14034950701356401.

Dahliani, S. P., \& Soemarno, I. (2016). Tantangan Keberadaan Rumah Lanting Sebagai Arsitektur Vernakular Tepi Air di Banjarmasin. Seminar Nasional - Semesta Arsitektur Nusantara 4. Malang: Jurusan Arsitektur Fakultas Teknik Universitas Brawijaya.

Hadinata, I. Y., \& Mentayani, I. (2018). Karakter Arsitektur Tepi Sungai di Kampung Sasirangan
Kota Banjarmasin. INFO TEKNIK , Vo19 (1) :87-100 .

Hamidah, N., Rijanta, R., Setiawan, B., \& Marfai, M. A. (2014). MODEL PERMUKIMAN KAWASAN TEPIAN SUNGAI KASUS: PERMUKIMAN TEPIAN SUNGAI KAHAYAN KOTA PALANGKARAYA (Urban Riverside Settlement ModelCase: Kahayan Riverside Settlement, Palangkaraya). Jurnal Permukiman , Vol. 9 (1 ) : 17-27. http://digilib.mercubuana.ac.id/manager/t!@file_ artikel_abstrak/Isi_Artikel_678019021114.pdf.

Kusnoto, Y., \& Purmintasari, Y. D. (2018). Pemukiman Awal Sungai Kapuas . Jurnal Ilmu-Ilmu Sosial Vol. 15(1) : 71-78.

Putro, J. D., \& Nurhamsyah, M. (2006). Pola Permukiman Tepian Air Studi Kasus : Desa Sepuk Laut, Punggur Besar dan Tanjung Saleh Kecamatan Sungai Kakap, Kabupaten Kubu Raya. Langkau Betang, Vol.2(1) pg:65-79.

Rengkung, J., Antariksa, Suryono, Nugroho, A. M., \& Kindangen, J. J. (2018). Architectural Typology Dwelling House of Minahasan Ethnic in Talawaan Village, district of North Minahasa, Indonesia . International Journal of Applied Engineering Research, Vol.13(2)pp.1007-1013.

Sari, I. K. (2014). Perubahan karakter arsitektur permukiman kampung beting kota Pontianak Kalimantan Barat. Langkau Betang , Vol.1(1) pp.62-75.

Setiadi, A. (2014). Tipologi dan Pola Penanganan Permukiman Kumuh di Kota Bontang. TATALOKA ， Vol.16 (4):220-233. https://www.researchgate.net/publication/298916 226_TIPOLOGI_DAN_POLA_PENANGANA N_PERMUKIMAN_KUMUH_DI_KOTA_BO NTANG_The_Typology_and_Patterns_of_Slum _Improvement_Management_in_Bontang_City. 
Suharjanto, G. (2013). Keterkaitan Tipologi Dengan Fungsi Dan Bentuk: Studi Kasus Bangunan Masjid. ComTech, 975-982.

Sulistijowati, M. (1991). Tipologi Arsitektur Pada Rumah Kolonial Surabaya (Dengan Kasus Perumahan Plampitan dan Sekitarnya).
Surabaya: Pusat Penelitian Institut Teknologi Sepuluh November.

Sunarningsih. (2011). Situs-situs Pemukiman Tepian Sungai di Kalimantan Selatan. Naditira Widya, Vol.5 (2)pp.182-194.

Suprijanto. (2001). Model Pengembangan Kawasan Tepi Air. KOLOKIUM Hasil Litbang PUSKIM. 